\title{
Influence of Reactive Ion Etching on THz Transmission and Reflection Properties of NiCr Film Deposited on a Dielectric Substrate
}

\author{
Jun GOU ${ }^{1}$ *, Jun WANG ${ }^{1}$, Wei Zhi LI ${ }^{1}$, Xiong Bang WEI ${ }^{2}$, Hui Ling TAI ${ }^{1}$, \\ De En GU ${ }^{1}$, Ya Dong JIANG ${ }^{1}$
}

\author{
${ }^{1}$ State Key Laboratory of Electronic Thin Films and Integrated Devices, University of Electronic Science and Technology \\ of China, No. 4, Section 2, North Jianshe Road, Chengdu 610054, China \\ ${ }^{2}$ School of Optoelectronic Information, University of Electronic Science and Technology of China, No. 4, Section 2, \\ North Jianshe Road, Chengdu 610054, China \\ crossref http://dx.doi.org/10.5755/j01.mm.21.2.6131
}

Received 06 January 2014; accepted 17 April 2014

\begin{abstract}
Enhanced terahertz (THz) absorption of $\mathrm{NiCr}$ film deposited on a dielectric substrate has been proven by applying a reactive ion etching (RIE) treatment to the dielectric film. Nano-scale nickel-chromium (NiCr) thin films are deposited on RIE treated silicon dioxide $\left(\mathrm{SiO}_{2}\right)$ dielectric substrates to study the transmission and reflection characteristics. Experimental results suggest that both transmission and reflection of $\mathrm{NiCr}$ film are weakened by the RIE treatment. The most significant decrease of transmission is observed in $(1 \sim 4) \mathrm{THz}$ while that of reflection occurs in $(1.7 \sim 2.5) \mathrm{THz}$ band. The decrease of both transmission and reflection is more significant for NiCr film with higher thickness. The RIE treatment, which induces a roughened surface of $\mathrm{SiO}_{2}$ substrate and increases the effective surface area of $\mathrm{NiCr}$ film, enhances the absorption and weakens the transmission and reflection of $\mathrm{THz}$ radiation.

Keywords: NiCr thin film, RIE, THz, transmission, reflection, absorption.
\end{abstract}

\section{INTRODUCTION}

Collection of terahertz $(\mathrm{THz})$ radiation is crucial because of its wide variety of applications in molecular spectroscopy, sensing, disease diagnostics, and biomedical imaging [1-3]. Metals are virtually perfect reflectors for $\mathrm{THz}$ radiation while metallic films have obvious transmission and absorption effects since the film thickness is much smaller than the skin depth of electromagnetic waves [4]. Recently, there is a widespread concern over nano-scale metallic film deposited on dielectric layer, which provides good $\mathrm{THz}$ absorption characteristics due to resistive loss in the film [5-6]. The absorption of metal film can be further improved by creating the so-called black metal [7] or producing absorbing structures (metamaterial film) [8-9]. A thin-film stack containing a dielectric Bragg reflector and a thin chromium metal film, has also been fabricated to absorb $20 \%$ of incident $\mathrm{THz}$ power in $(3 \sim 5) \mathrm{THz}$ [10]. We have suggested an effective way in [11] to enhance $\mathrm{THz}$ absorption of nickelchromium (NiCr) thin film in microbolometer infrared focal plane arrays (IRFPA) by applying a reactive ion etching (RIE) process to the dielectric support layer. However, the influence of RIE on $\mathrm{THz}$ transmission and reflection properties of $\mathrm{NiCr}$ film is still unclear.

In this paper, NiCr films are deposited on untreated and RIE treated silicon dioxide $\left(\mathrm{SiO}_{2}\right)$ dielectric substrates with different thicknesses. $\mathrm{THz}$ transmission and reflection characteristics of the films are reported.

\section{EXPERIMENTAL}

$\mathrm{SiO}_{2}$ thin films were deposited from $\mathrm{SiH}_{4} / \mathrm{N}_{2} \mathrm{O}$ by plasma enhanced chemical vapor deposition (PECVD) at a

\footnotetext{
* Corresponding author. Tel.: +86-288-3207086-605; fax.: +86-2883206123. E-mail address: goujun@yeah.net (J. Gou)
}

temperature of $350^{\circ} \mathrm{C}$. $\mathrm{SiO}_{2}$ thin films with thicknesses of $100 \mathrm{~nm}$ and $150 \mathrm{~nm}$ were prepared on p-type silicon (100) wafers, respectively. The extra $50 \mathrm{~nm}$ of the $150 \mathrm{~nm}$ films was etched away by a RIE system (FHR $150 \times 4)$ using a gas mixture of $\mathrm{CHF}_{3}$ and $\mathrm{O}_{2}$, which provided a $\mathrm{SiO}_{2}$ etch rate of $40 \mathrm{~nm} / \mathrm{min}$ for a RF power of $400 \mathrm{~W}$, a pressure of $4 \mathrm{~Pa}$, a $\mathrm{CHF}_{3}$ flow of $20 \mathrm{sccm}$, an $\mathrm{O}_{2}$ flow of $3 \mathrm{sccm}$, a chamber temperature of $40^{\circ} \mathrm{C}$, and a substrate temperature of $5^{\circ} \mathrm{C}$. $\mathrm{NiCr}(\mathrm{Ni}: \mathrm{Cr}=80: 20)$ films were prepared on the untreated and RIE treated $\mathrm{SiO}_{2}$ substrates by reactive sputtering of a high purity NiCr target in an Ar atmosphere. $\mathrm{NiCr}$ films with different thicknesses $(8 \mathrm{~nm}, 16 \mathrm{~nm}$, and $24 \mathrm{~nm}$ ) were deposited by controlling sputtering time. The thicknesses of the obtained $\mathrm{NiCr}$ films were measured by a XP-200 step profiler and verified by sheet resistance tests.

Transmissions of the films were measured by a Fourier transform infrared spectroscopy (FTIR) system (Perkin Elmer Spectrum 400) while reflection measurements were taken by a THz time-domain spectroscopy (THz-TDS) system (EKSPLA) with an incident angle of 30 degree.

\section{RESULTS AND DISCUSSION}

The measured transmission curves of $\mathrm{NiCr}$ films with thicknesses of $8 \mathrm{~nm}, 16 \mathrm{~nm}$ and $24 \mathrm{~nm}$ deposited on untreated and RIE treated $\mathrm{SiO}_{2}$ films are shown in Fig. 1. It suggests that the transmission of NiCr film deposited on a RIE treated $\mathrm{SiO}_{2}$ film for each thickness is lower compared to that of NiCr film deposited on an untreated $\mathrm{SiO}_{2}$ film. For spectral range of $(1 \sim 12) \mathrm{THz}$, the decrease of transmission in $(1 \sim 4) \mathrm{THz}$ is more significant compared to the decrease in higher frequency.

The measured reflection curves of $\mathrm{NiCr}$ films with thicknesses of $8 \mathrm{~nm}, 16 \mathrm{~nm}$ and $24 \mathrm{~nm}$ deposited on untreated and RIE treated $\mathrm{SiO}_{2}$ films are shown in Fig. 2. It can be seen that the reflection is also weakened in general by 
the RIE treatment and the most significant decrease occurs at $(1.7 \sim 2.5) \mathrm{THz}$. The decreases of both transmission and reflection induced by the RIE treatment are more significant for NiCr film with a higher film thickness.

For NiCr film deposited on a dielectric substrate, absorption $(A)$, transmission $(T)$, and reflection $(R)$ have the following relationship: $A+T+R=1$. It can be concluded from the transmission and reflection curves that the absorption of $\mathrm{NiCr}$ film is enhanced for the transmission and reflection are both decreased due to the RIE treatment applied to the $\mathrm{SiO}_{2}$ dielectric support film. This agrees with our earlier research reported in [11].

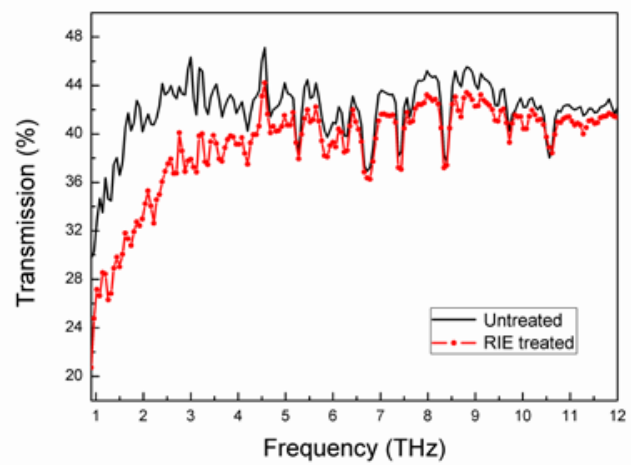

a

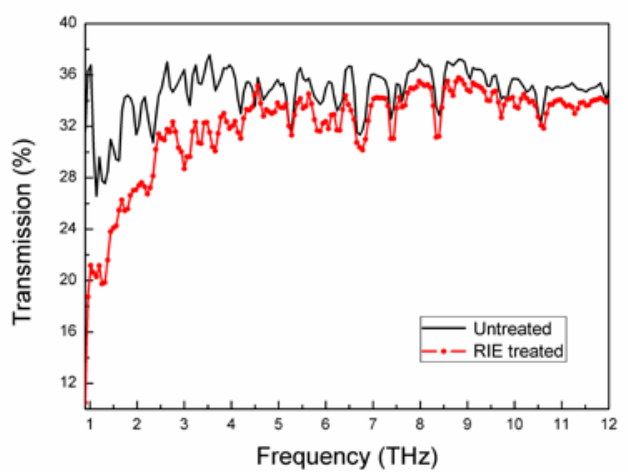

$\mathrm{b}$

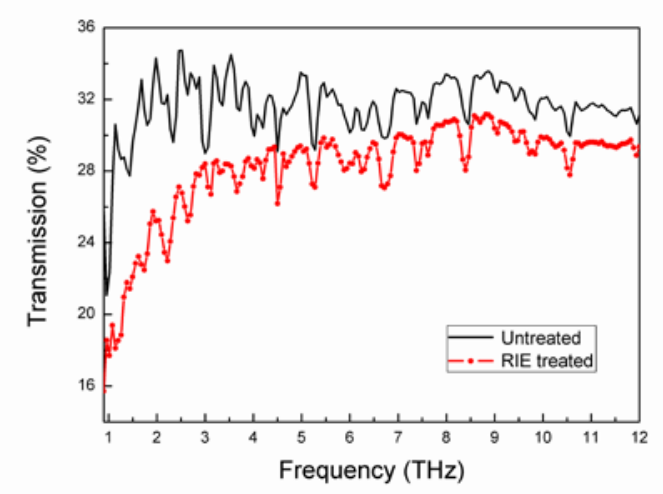

C

Fig. 1. The measured transmission curves of $\mathrm{NiCr}$ films in $(1 \sim 12) \mathrm{THz}$ with a thickness of $8 \mathrm{~nm}$ (a), $16 \mathrm{~nm}$ (b), and $24 \mathrm{~nm}$ (c) deposited on untreated $\mathrm{SiO}_{2}$ films and RIE treated $\mathrm{SiO}_{2}$ films

Fig. 3 shows the AFM images of $\mathrm{NiCr}$ films with thicknesses of $8 \mathrm{~nm}, 16 \mathrm{~nm}$ and $24 \mathrm{~nm}$ on untreated $\mathrm{SiO}_{2}$ films and RIE treated $\mathrm{SiO}_{2}$ films. It can be seen that for NiCr films with different thicknesses, roughened surfaces are induced by the RIE treatments. The effective surface area of NiCr film is increased due to nano - scale surface structures. The absorption of a metal film $(A)$ consists of two components [12]: $A=A_{\text {INTR }}+A_{\text {Ss, }}$, where $A_{\text {INTR }}$ is the intrinsic absorption of an ideally smooth surface and $A_{\mathrm{Ss}}$ is the contribution due to nano-scale surface structures. It becomes clear that $\mathrm{THz}$ transmission and reflection of $\mathrm{NiCr}$ film are both decreased after RIE treatment mainly due to the enhanced absorption $\left(A_{\mathrm{SS}}\right)$.

In order to study the effect of RIE process on the dielectric substrate, AFM tests were done on RIE treated and untreated $\mathrm{SiO}_{2}$ films, as shown in Fig. 4. It can be seen that a roughened surface of $\mathrm{SiO}_{2}$ film with nano-scale surface structures is induced by the RIE treatment, which results in nanostructured $\mathrm{NiCr}$ film which is deposited on the RIE treated $\mathrm{SiO}_{2}$ film later.
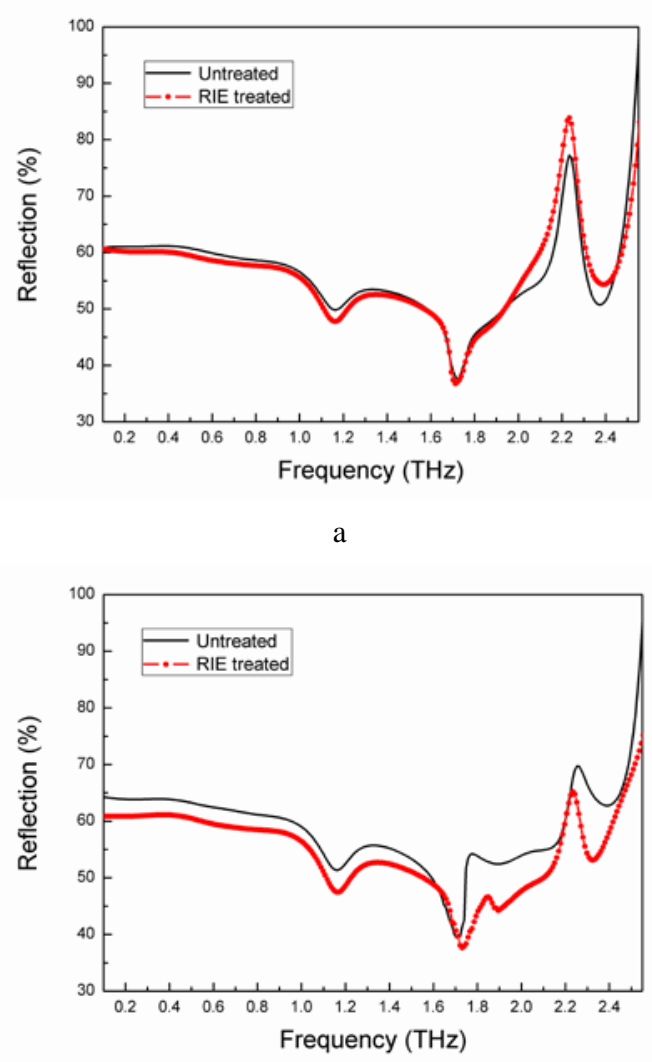

b

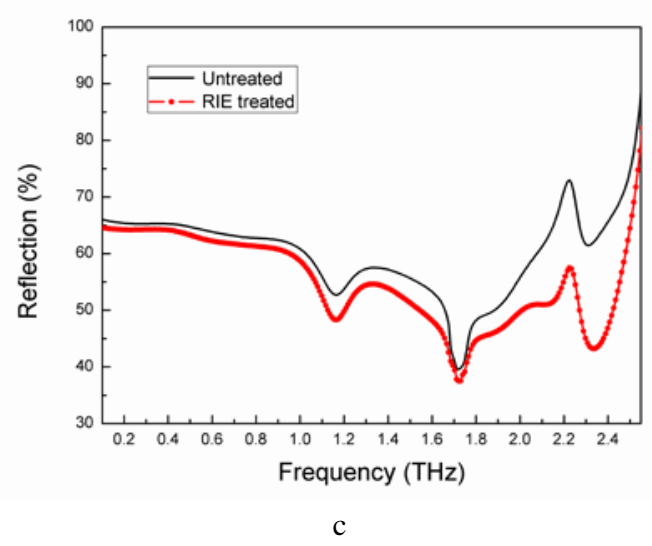

Fig. 2. The measured reflection curves of $\mathrm{NiCr}$ films in $(0.1 \sim 2.55) \mathrm{THz}$ with a thickness of $8 \mathrm{~nm}$ (a), $16 \mathrm{~nm}$ (b), and $24 \mathrm{~nm}$ (c) deposited on untreated $\mathrm{SiO}_{2}$ films and RIE treated $\mathrm{SiO}_{2}$ films 

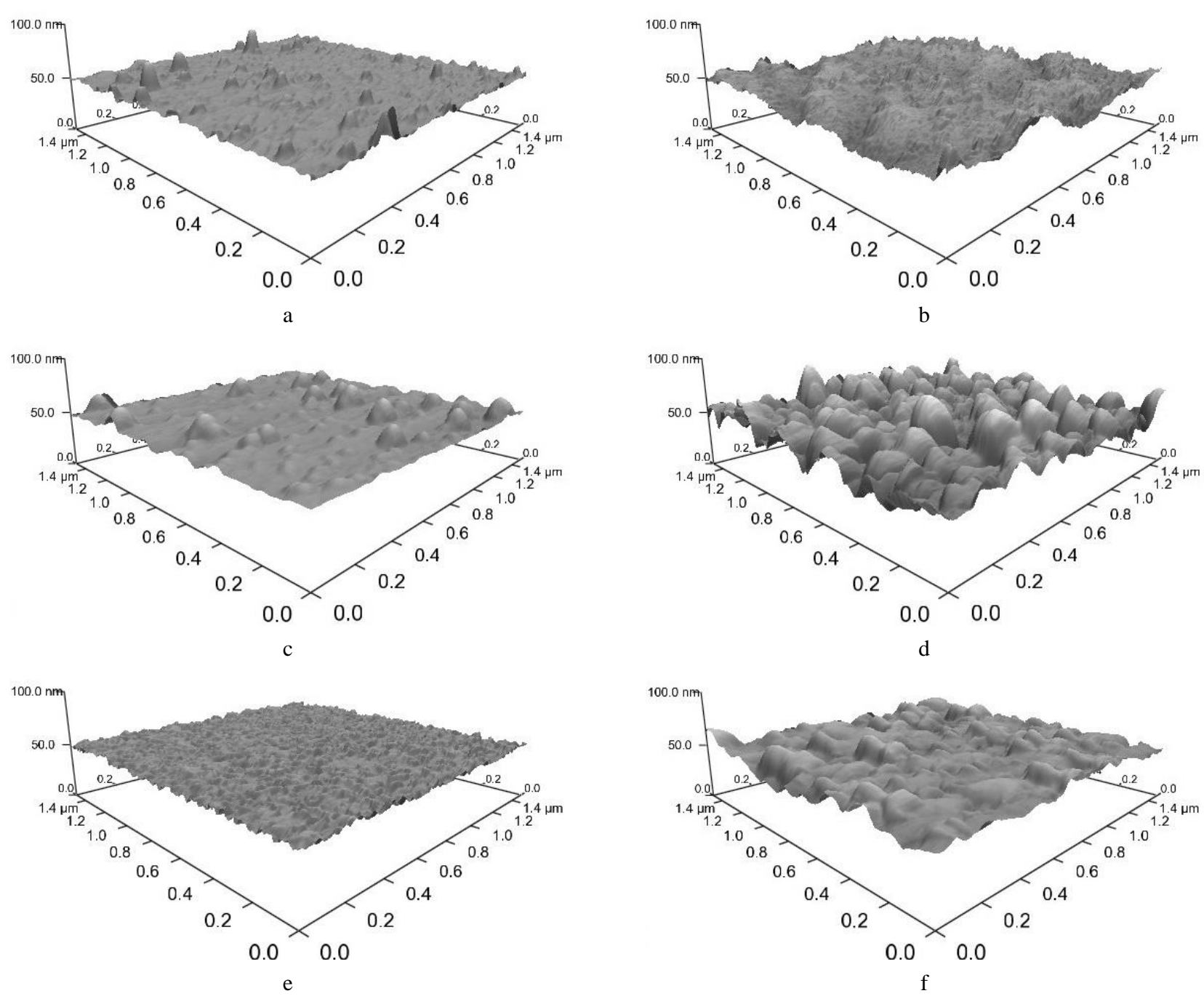

Fig. 3. AFM images of $\mathrm{NiCr}$ films with different thickness deposited on untreated and $\mathrm{RIE}$ treated $\mathrm{SiO}_{2}$ films: a $-8 \mathrm{~nm} \mathrm{NiCr}$ film on a untreated $\mathrm{SiO}_{2}$ film; b - $8 \mathrm{~nm}$ NiCr film on a RIE treated $\mathrm{SiO}_{2}$ film; c - $16 \mathrm{~nm} \mathrm{NiCr}$ film on a untreated $\mathrm{SiO}_{2}$ film; d $-16 \mathrm{~nm} \mathrm{NiCr}$ film on a RIE treated $\mathrm{SiO}_{2}$ film; e - $24 \mathrm{~nm}$ NiCr film on a untreated $\mathrm{SiO}_{2}$ film; f - $24 \mathrm{~nm} \mathrm{NiCr}$ film on a RIE treated $\mathrm{SiO}_{2}$ film
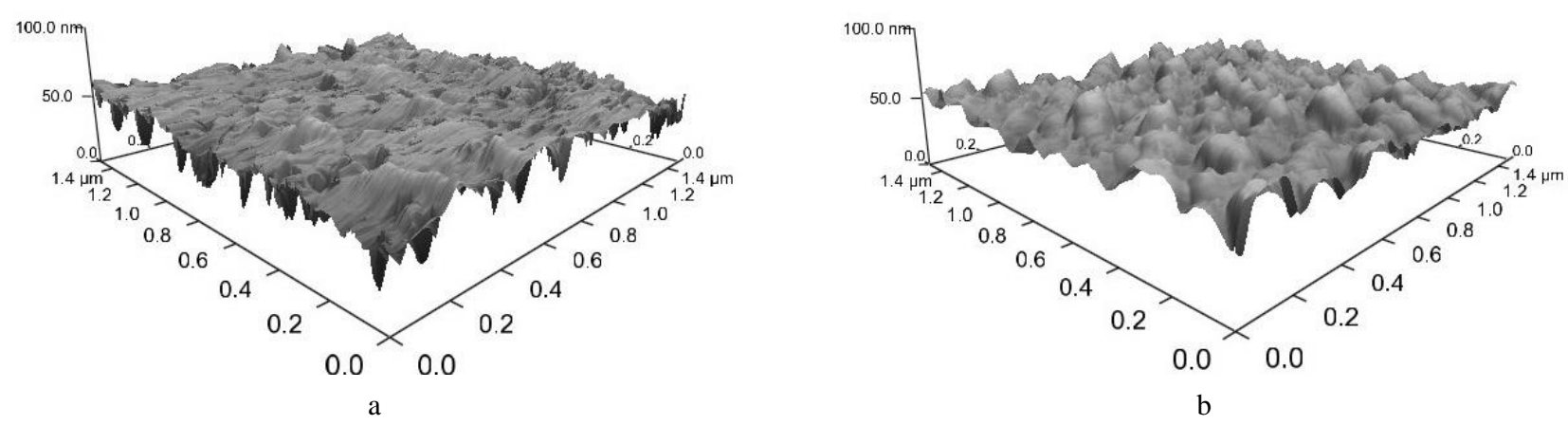

Fig. 4. AFM images of untreated $\mathrm{SiO}_{2}$ film (a) and $\mathrm{RIE}$ treated $\mathrm{SiO}_{2}$ film (b)

\section{CONCLUSIONS}

A MEMS-compatible process was suggested to improve $\mathrm{THz}$ absorption of metal film by applying a reactive ion etching (RIE) process to the dielectric support layer. To study the influence of RIE on $\mathrm{THz}$ transmission and reflection characteristics of metal film, RIE treatments were applied to $\mathrm{SiO}_{2}$ dielectric substrates of nano - scale NiCr thin films with different thicknesses. Experimental results suggested that both transmission and reflection of
NiCr film deposited on a RIE treated $\mathrm{SiO}_{2}$ film were weakened compared to that of NiCr film deposited on an untreated $\mathrm{SiO}_{2}$ film due to enhanced absorption. $\mathrm{SiO}_{2}$ film surface was roughened by the RIE treatment which resulted in nanostructured NiCr film with a larger effective absorption area. More significant decreases of transmission and reflection were achieved for $\mathrm{NiCr}$ film with higher thickness. The most significant decreases of transmission and reflection occurred at $(1 \sim 4) \mathrm{THz}$ and $(1.7 \sim 2.5) \mathrm{THz}$ band in the measurements, respectively. 


\section{Acknowledgments}

The authors thank Programs of National Natural Science Foundation of China (Grant \#61235006, 61006036 and 61101030) and National Higher-education Institution General Research and Development Funding (ZYGX2013J063) for their financial supports.

\section{REFERENCES}

1. Chen, H. T., O’Hara, J. F., Azad, A. K., Taylor, A. J., Averitt, R. D., $\quad$ Shrekenhamer, D. B., $\quad$ Padilla, W. J. Experimental Demonstration of Frequency-agile Terahertz Metamaterials Nature Photonics 2 (5) 2008: pp. 295-298.

2. Williams, C. R., Andrews, S. R., Maier, S. A., FernandezDominguez, A. I., Martin-Moreno, L., Garcia-Vidal, F. J. Highly Confined Guiding of Terahertz Surface Plasmon Polaritons on Structured Metal Surfaces Nature Photonics 2 (3) 2008: pp. 175-179.

3. Siegel, P. H. Terahertz Technology IEEE Transactions on Microwave Theory and Techniques 50 2002: pp. 910-928. http://dx.doi.org/10.1109/22.989974

4. Liu, Z. M., Du, H., Si, N. L., Wen, L. S. The Influence of Size Effect of Conductivity on the Microwave Absorption Properties of Thin Al Film Acta Metallurgica Sinica 44 (9) 2008: pp. 1099-1104.

5. Bolakis, C., Grbovic, D., Lavrik, N. V., Karunasiri, G. Design and Characterization of Terahertz-absorbing Nanolaminates of Dielectric and Metal Thin Films Optics Express 18 2010: pp. 14488-14495.
6. Alves, F., Karamitros, A., Grbovic, D., Kearney, B., Karunasiri, G. Highly Absorbing Nano-scale Metal Films for Terahertz Applications Optical Engineering 51 2012: pp. 063801-1-063801-6.

7. Vorobyev, A. Y., Guo, C. Colorizing Metals with Femtosecond Laser Pulses Applied Physics Letters 92 (4) 2008: pp. 041914-1 -041914-3.

8. Kearney, B., Alves, F., Grbovic, D., Karunasiri, G. Tunable $\mathrm{THz}$ Absorption Using $\mathrm{Al} / \mathrm{SiO}_{\mathrm{x}}$ Planar Periodic Structures Proceedings of SPIE 8363 2012: pp. 836309-1-836309-6.

9. Wen, Q. Y., Zhang, H. W., Xie, Y. S., Yang, Q. H., Liu, Y. L. Dual Band Terahertz Metamaterial Absorber: Design, Fabrication, and Characterization Applied Physics Letters 95 2009: pp. 241111-1-241111-3.

10. Bolakis, C., Grbovic, D., Lavrik, N. V., Karunasiri, G. Design and Characterization of Terahertz Absorbing Nanolaminates of Dielectric and Metal Thin Films Optics Express 18 2010: pp. 14488-14495.

11. Gou, J., Wang, J., Li, W. Z., Tai, H. L., Gu, D. E., Jiang, Y. D. Terahertz Absorption Characteristics of NiCr Film and Enhanced Absorption by Reactive Ion Etching in a Microbolometer Focal Plane Array Journal of Infrared, Millimeter, and Terahertz Waves 34 2013: pp. 431-436.

12. Vorobyev, A. Y., Topkov, A. N., Gurin, O. V., Svich, V. A., Guo, C. L. Enhanced Absorption of Metals over Ultrabroad Electromagnetic Spectrum Applied Physics Letters 95 2009: pp. 121106-1-121106-3. 